\title{
Implications of ocean bottom temperatures on the catch ability of American lobster
}

\author{
Xiaoxu Zhao ${ }^{*}$, Pengwen Ding ${ }^{1}$, Jilei Pang ${ }^{1}$ \\ ${ }^{1}$ College of Geometics of Shandong University of Science and Technology, China
}

\begin{abstract}
Since the beginning of the satellite era, the general trend of global and regional sea-surface temperature (SST) have continued to rise and, in the recent decade, the rate of warming has increased dramatically in the Gulf of Maine. However, due to variations in thermal stratification in the water column, SST is not the best measure to determine the impact on benthic organisms. So understanding the spatial and temporal variations of the ocean bottom temperature is critical to fisheries management. Since 2001, the Environmental Monitors on Lobster Traps (eMOLT) project has been implemented. The lobster fishermen have volunteered to collect bottom temperature and American lobster catch data from dozens of locations off the New England coast. Now we can use these data to analyze the relationship between ocean bottom temperature and lobster catch. Using data collected over the past decade, we examine the effect of temperature, temperature change, soak time and other factors on the catchability of lobsters. Our results suggest that there is a increase in catchability at the same time there is a) a temperature rise over many years and b) day-to-day temperature changes.
\end{abstract}

\section{Introduction}

In the past decade, the global sea surface temperature (SST) has warmed at $0.01{ }^{\circ} \mathrm{C}$ per year ${ }^{[1]}$. The northwest Atlantic has experienced ocean warming rates in the top $1 \%$ globally at $0.03{ }^{\circ} \mathrm{C}$ per year. Both global and regional SST continue to break recordsand the rate of warming has increased compared to earlier long-term trends. However, due to thermal stratification there is a decoupling of various layers if the water column so that bottom temperature is a better standard for analyzing benthic organisms such as lobsters ${ }^{[2]}$. This paper analyzes the effect of ocean bottom temperature on lobster catch.

Since lobster fishermen already work long hours at sea and are most interested in the conditions at the bottom, the Environmental Monitors on Lobster Traps (eMOLT) project was implemented in 2001. Since that time approximately 60 lobster fisherman scattered along the New England coast have attached low-cost sensors (with $0.2{ }^{\circ} \mathrm{C}$ accuracy) to their traps on the bottom of the ocean. So far, the database contains more than 6 million hours of temperature data and is making contributions to NOAA's Integrated Ocean Observing System (IOOS).

\section{American lobster}

The American lobster (Homarus americanus) is mainly distributed from New Jersey, US to Newfoundland, Canada. Lobsters are a benthic species that usually in waters less than 100 meters deep. The world's growing demand has led to the further development of fishery products, mechanical design of traps, and fishing strategies. For more than 150 years, New England fishermen have been curious about the daily changes in catch and what drives it. They understand there is a complex set of factors. There is the effects of lobster biology (molting, natural reproduction and shedding cycles), environment (temperature, habitat), and lobster density. It is fairly well resolved that temperature has a significant effect on the physiology, behavior and ecology of lobster. Avoiding extreme temperatures or using behavioral temperature regulation to control body temperature affects the distribution. Some studies have analyzed the effect of temperature on lobster capture. They have found that the catchability of lobsters varies with temperature ${ }^{[3]}$. Lab studies have shown that the lobsters activity measured by walking speed depends on the temperature and assumes that the greater the activity, the higher the capture rate, because the more active the lobsters, the more likely they are to encounter traps.

This paper analyzes the long-term measured data of three sites (BN01, BD01, and TS02)off the New England coast in water depths of 20,11, and 8 meters from 2001 to the present (Fig.1.). We explore the potential effects of ocean bottom temperature on lobster catch.

*Corresponding author: 1130736692@qq.com 


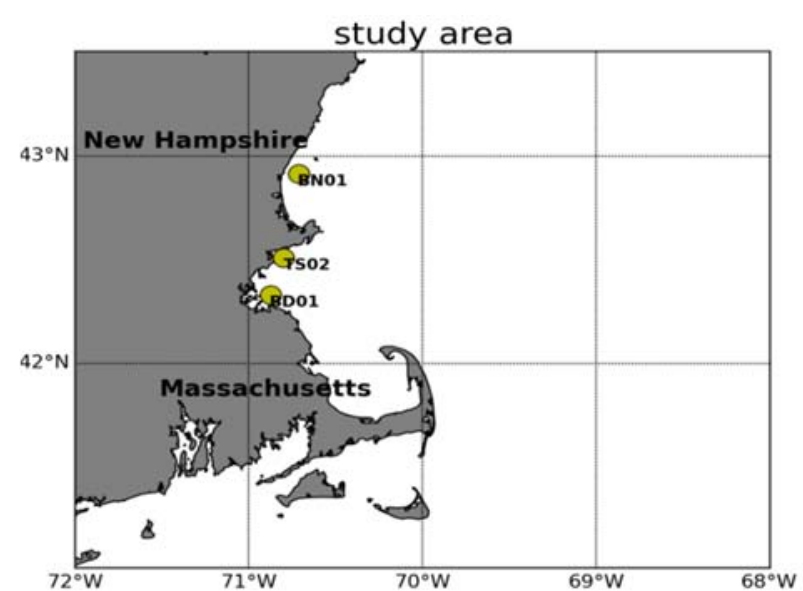

Fig.1. Study area (BN01, BD01, TS02), the depth of the bottom placed by the lobster trap is $20,11,8$ meters

\section{Data processing}

\subsection{Data Sources}

In the eMOLT project, 60 lobster fishermen voluntarily provided long-term catch and bottom temperature data. Lobsters fishermen installed temperature sensors (ONSET TidBits and VEMCO Minilogs) in lobster traps to obtain hourly bottom temperature data with an accuracy of less than $0.2^{\circ} \mathrm{C}$ (Fig.2.). The advantage of this temperature sensor is low cost, high precision, and good operating conditions. Each lobster fisherman will place a lobster trap at different depths on the seabed at afixed location. The soak time of the lobster trap is not fixed, and most lobsters will soak the lobster trap for 1 to 20 days.

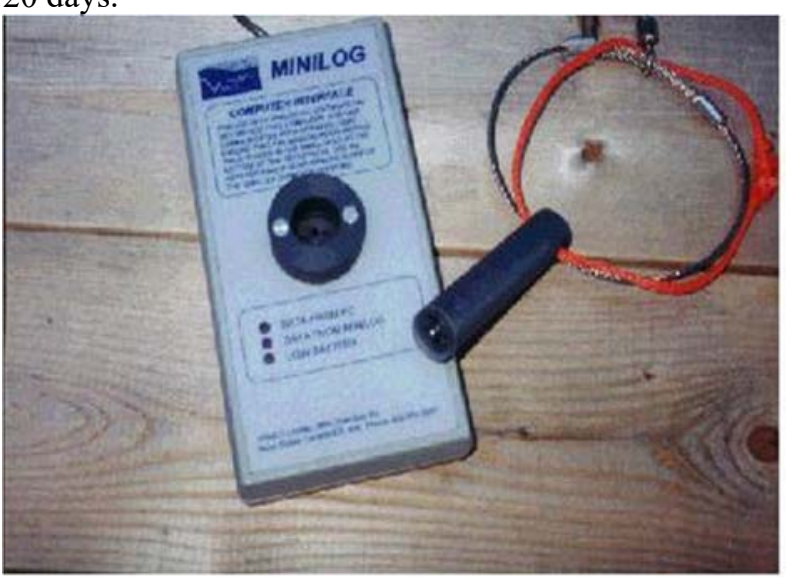

Fig.2. Miniature temperature sensor

\subsection{Data preprocessing}

The catch and the hourly ocean bottom temperatures recorded by fishemern at BN01, BD01 and TS02 were extracted from the NOAA database (Table 1).

Table 1. Lobster temperature and catch

\begin{tabular}{|c|c|c|c|c|c|c|c|}
\hline sites & latitude & longitude & data & depth & number of trap & number of catch per haul & mean temperature $\left({ }^{\circ} \mathrm{F}\right)$ \\
\hline BN01 & 4254.86 & 7042.57 & $2002-08-01: 06: 59$ & 20 & 8 & 15 & 46.555 \\
\hline BD01 & 4219.9 & 7052.50 & $2002-06-13: 10: 00$ & 11 & 12 & 7 & 53.1343 \\
\hline TS02 & 4230.73 & 7047.97 & $2007-07-18: 07: 56$ & 8 & 15 & 5 & 51.5058 \\
\hline
\end{tabular}

\section{Analysis}

This paper uses cross-correlation analysis to analyze long-term data on bottom temperature and lobster catch in Maine, USA ${ }^{[4]}$.Due to the bad weather, mechanical problems or human factors, the soak time of lobster traps in the sea is not fixed. This paper assumes that the small difference between the soaking time and the precise fixed soaking time has negligible effect on the lobster catch and does not correct these differences ${ }^{[5]}$.

\subsection{Influence of bottom temperature on lobster catch}

We calculated the mean bottom temperature for each lobster trap in the sea during every soak time, comparing the mean catch of each lobster trap.

\subsubsection{Mean bottom temperature for each fishing}

\section{Temperature}

Our moving average of temperature and catch is set to 6 degrees, so that we can see the general trend of the catch as the temperature rises, and we can see the details of some changes. It can be seen that the catch of each lobster trap increases with the increase of bottom temperature. When the temperature is around 53 degrees, the lobster catch reaches the peak (Fig.3). Due to the limitation of data, it is impossible to analyze the lobster after 60 degrees. We need more data on the trend of catch volume as a function of temperature.

Temperature change

Our moving average of temperature changes and captures is set to 3 degrees, with some indications that the catch increases after positive and negative 
temperature changes, in other words, the lobsters begin to move at cooling and heating temperatures and are exposed to traps. We make this a smile hypothesis. This is because of the preference of lobsters for thermal preferences, thermal preferences may influence the movement of lobsters in thermally heterogeneous habitats ${ }^{[6]}$.

\section{Lobster trap soaking time}

In the early stage of immersion time in the sea, the lobster catch of each trap increased with the increase of soaking time. At about eight days, the average lobster catch of each trap reached a peak and then decreased. Because the longer the soaking time, the bait in the lobster trap is evidently depleted and will not attract more lobsters.
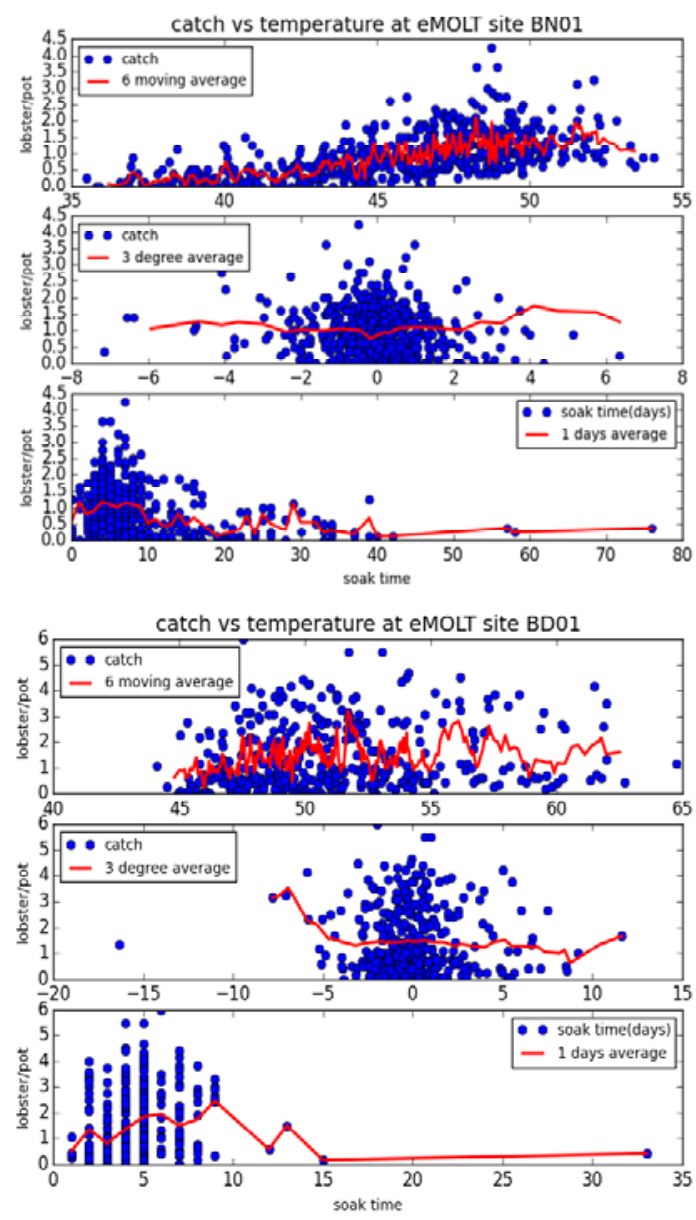

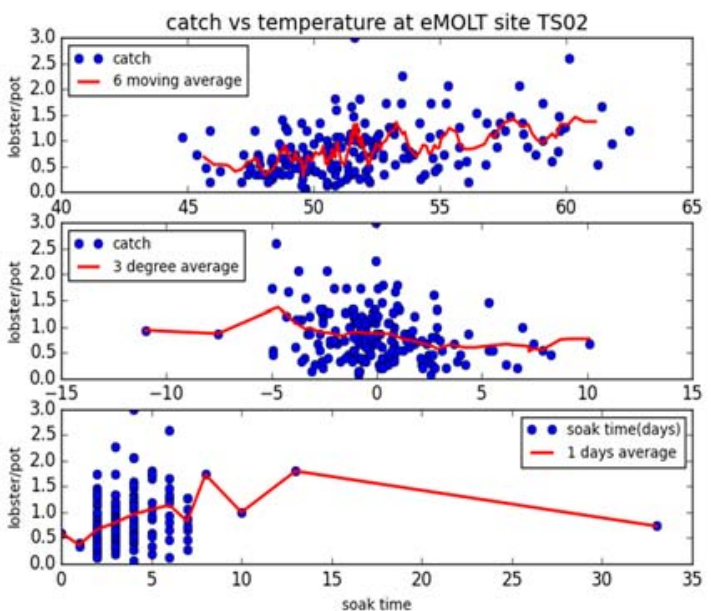

Fig.3. BN01, BD01, TS02 lobster average catch and average temperature, temperature change, immersion time scatter plot.The red line is the moving average. The top two panels $\mathrm{x}$ axis units are Farenheit (units understood by local fishermen).

\subsection{The impact of storms on lobster catch}

In Figure 4 the effect of a storm in October 2005 at another location is depicted. The bottom temperature after the storm has a significant decline. This is evidently a case of cold water upwelling into the area of the trap where the thermocline moves shoreward away from the trap. When the temperature drops suddenly, the lobster will likely increase its foraging activity in an effort to find comfortable temperatures. This temperature change exacerbates the activity of the lobster. The capture rate is affected and the chance of lobster entering the lobster cage is increased. Some studies have also shown that there is a significant decrease in the sea bottom temperature after the storm passes ${ }^{[7]}$. Figure 5 shows the changes in the average lobster capture before and after the six different storms, with four distinct changes after the storm.

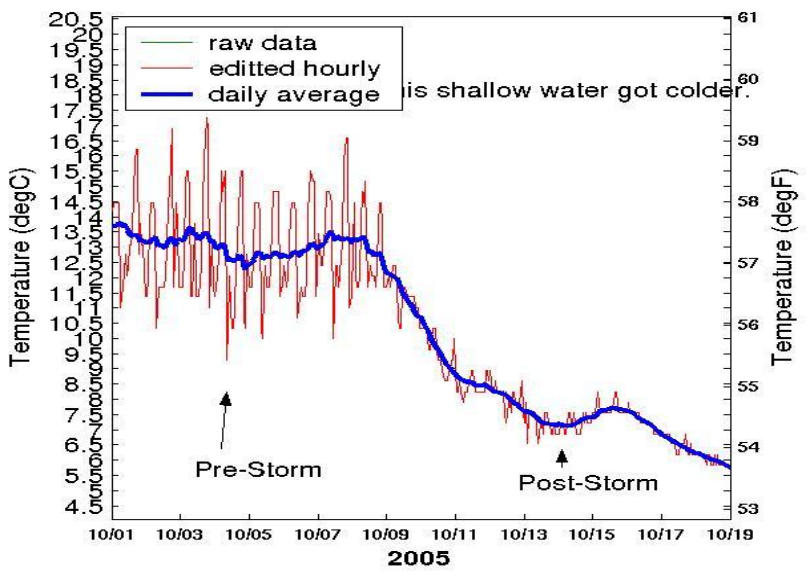

Fig.4. An example of a trap located in front of a storm (with tidal changes) before the storm, and then on the colder side in front of the storm. These events may trigger changes in fishing rates. 

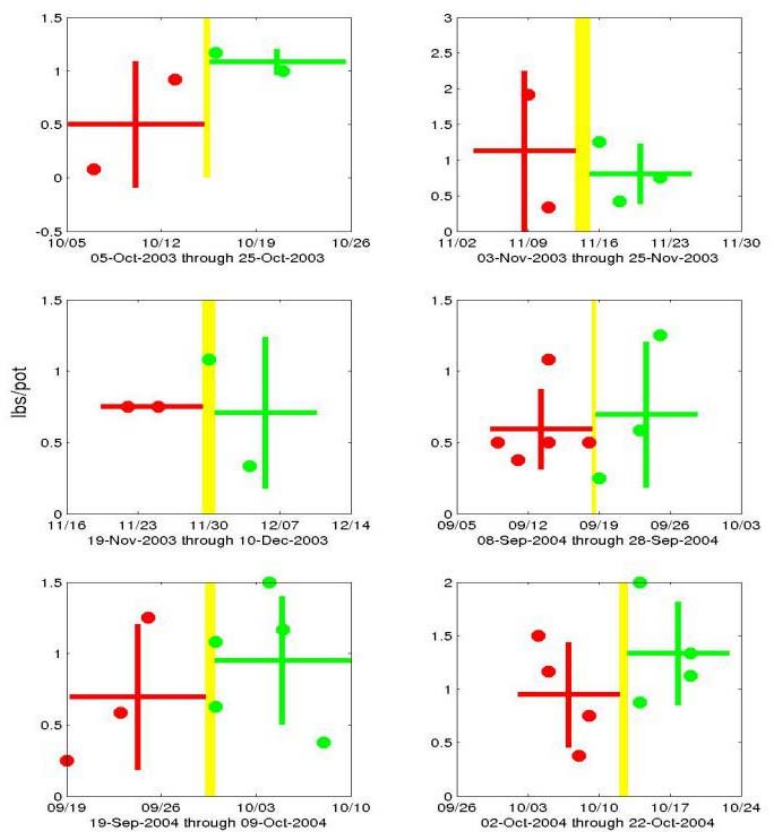

Fig.5. Capture (point) and capture mean (horizontal bar) and standard deviation (vertical bar) before (red) and after (green) storm (yellow).

\section{Conclusion}

Due to the complexity of the marine environment and lobster ecology, it is difficult to find consistent catch vs temperature correlations for depths, regions and time scales. We suggest that temperature changes may increase the tendency of lobsters to enter the trap. And, in general, the catch peaked at $12^{\circ} \mathrm{C}$, The data suggest the peak in catch occurred near 8 days of soak time.

On the one hand, because lobster metabolism increases with the increases temperature, their body temperature will also increase, making them more active and need more food, which may increase catchability. On the other hand, lobsters are able to detect very small temperature changes, and it is clear that this information can be used to select certain temperatures rather than other temperatures, thus causing the migration of lobsters and increasing the likelihood of encountering traps. The increase in lobster catch after storm could proves this hypothesis but more data is needed. This requires more lobster biology to follow up on this study. We hope this article can help in the understanding of lobsters coping with temperature changes especially if the temperature continues to rise. More work is needed to make solid contributions to the sustainable development of the lobster science and industry.

\section{References}

1. Pershing AJ,Alexander MA, Hernandez CM, Kerr LA, Le Bris A, Mills KE, Nye JA, Record NR, Scannell HA,Scott JD, Sherwood GD, Thomas AC. 2015. Slow adaptation in the face of rapid warming leads of collapse of the Gulf of Maine cod fishery. Science.13; 350(6262):809-12. doi.org / 10.1126/ science.aac9819.

2. Arnault Le Bris, a,* Andrew J. Pershing ${ }^{\mathrm{a}}$, Julien Gaudette $^{\mathrm{b}}$. Multi-scale quantification of the effects of temperature on size atmaturity in the American lobster (Homarus americanus) Fisheries Research 186 (2017) 397-406.

3. D. W. MCLEESE, AND D. G. WILDER.The Activity and Catchability of the Lobster (Homarus americanus) in Relation to Temperature.J.FISH. RES. BD. CANADA, 15 (6), pp. 1345-1354, 1958.

4. A.CAMPBELL, D.J.NOAKES, ANDR.W.EINER. Temperature and lobster, Homarus arnericanus, yield relationships.Can.J.Fish.Aquat.Sci.48:20732082.

5. K. F. DRINKWATER, ${ }^{1, *}$ M. J. TREMBLAY ${ }^{2}$ AND M. COMEAU ${ }^{3}$ The influence of wind and temperature on the catch rate of the American lobster (Homarus americanus) during spring fisheries off eastern Canada.Fish. Oceanogr. 15:2, 150-165, 2006.

6. Steven H. Jury, ${ }^{\mathrm{a}, *}$ Winsor H. ,Watson III $^{\mathrm{b}}$.Seasonal and sexual differences in the thermal preferences and movements of American lobsters.Canadian Journal of Fisheries and Aquatic Sciences, 2013, 70(11): 1650-1657.

7. Chunhua Qiu. Influence of Typhoon on Seafloor temperature of Continental Shelf [A]. Chinese Society of Oceanology and Limnology, Institute of Oceanology of the Chinese Academy of Sciences. Proceedings of the 10th National Congress and Academic Symposium of China Ocean and Limnology Society [C]. Chinese Society of Oceanology and Limnology, Institute of Oceanology of the Chinese Academy of Sciences: 2012: 1. 